\title{
A contingency analysis of taste aversion conditioning
}

\author{
BARRY MONROE and LEWIS M. BARKER \\ Baylor University, Waco, Texas 76703
}

\begin{abstract}
The acquisition of conditioned taste aversion was assessed relative to five control procedures. That is, forward conditioning using multiple-trial, brief-duration taste CSs and weak USs over a 30-min CS-US delay was compared to backward, CS alone, US alone, sham CS and sham US, and random control procedures. The outcome supported an associative conditioning interpretation of the learned aversion. While there were no differences between the various control procedures, all were different from the forward conditioning group. The argument was made that some of the distinctive associative and nonassociative phenomena attributed to taste aversion conditioning (but not seen in the present study) may in part be due to the duration and intensity of both the CS and US events.
\end{abstract}

Taste aversion conditioning has come to be an increasingly popular paradigm within animal learning. Recently, there has been criticism concerning the adequacy of control procedures for the one-trial, longdelay design most often used in taste aversion conditioning (Bitterman, 1976; Mitchell, 1977, 1978). The controversy apparently centers around whether the phenomenon in question is ascribable to nonassociative or associative factors. The present paper is concerned with the question of control groups that allow for an associative conditioning interpretation of longdelay learning.

Some of the earliest investigations of taste aversion conditioning used traditional Pavlovian conditioning controls, such as sham CS and sham US groups (Garcia, Kimeldorf, \& Koelling, 1955) and temporal controls including backward conditioning groups (Garcia \& Kimeldorf, 1957). To date, however, a Pavlovian analysis including the use of truly random control groups, as suggested by Rescorla (1967), has not been reported. Presumably this is due to the oneirial nature of taste aversion conditioning which makes difficult the sequencing of CSs and USs necessary for a truly random group.

The present experiment presents a new approach to this problem. By fractionating the CS and US events (using small amounts of the CS solution, and small doses of poison), the course of acquisition of flavor aversion conditioning was sufficiently retarded to use controls appropriate for multiple-trial experiments. Specifically, a random control procedure was used in which the occurrence of the CS (flavor) provided no information about a subsequent occur-

This research was presented at the Southwestern Psychological Association meeting in New Orleans, 1978. Requests for reprints should be addressed to the second author, Department of Psychology, Box 183, Baylor University, Waco, Texas 76703 . rence of the US (cf. Rescorla, 1967). This procedure was compared to other control procedures and to a forward conditioning group.

\section{METHOD}

\section{Subjects}

Forty-eight laboratory-born rats of both sexes served as subjects. The rats were approximately 60 days old and were the second-generation offspring of a cross between albinos and wildtrapped rats (Rattus norvegicus).

\section{Apparatus}

The subjects were tested in a plexiglas box measuring $27 \mathrm{~cm}$ long, $15 \mathrm{~cm}$ high, and $10 \mathrm{~cm}$ wide, fitted at one end with two glass Richter tubes. A $.25 \%$ saccharin solution was used for training and testing purposes, while $.15 \mathrm{M} \mathrm{LiCl}$ served as the toxic agent. The saccharin solution was administered orally during training via a $1.0-\mathrm{ml}$ disposable syringe.

\section{Procedure}

The subjects were divided into six groups, one experimental and five controls, each having eight animals. All subjects were provided ad-lib Purina Chow and tap water throughout the course of the experiment. Treatment of all groups consisted of one CS and one US presentation per day-only the sequencing of the CS and US varied between groups.

The forward conditioning treatment (Group FOR) employed a 30-min CS-US interval. The control procedures were as follows: (1) backward conditioning (Group BKD), US-CS interval = $30 \mathrm{~min}$; (2) CS alone (Group CSA), saline injected $30 \mathrm{~min}$ following CS; (3) US alone (Group USA), oral water rinse $30 \mathrm{~min}$ before toxin; (4) sham treatment (Group SHAM), oral water rinse followed $30 \mathrm{~min}$ later by saline injection; (5) random treatment (Group RAN), CS precedes or follows US randomly, determined in the following manner. An experimental session between 0800 $1600 \mathrm{~h}$ was divided into 3215 -min intervals. One CS time and one US time for each treatment day was independently selected from these 32 intervals from a table of random numbers. On a given day, therefore, a CS could precede or follow a US by no less than $15 \mathrm{~min}$ and no more than $8 \mathrm{~h}$.

Appropriate pairings for the other groups were based upon the randomly determined CS times of Group RAN. That is, if, on a given day, the CS treatment time of Group RAN was 11:30, other treatment groups' CS periods were approximately 11:30, and the US events were sequenced accordingly. 
Training sessions were conducted, one trial per day for 8 days. The CS for Groups FOR, BKD, CSA, and RAN was $1.0 \mathrm{ml}$ of the saccharin solution administered orally via syringe. The sham CS for Groups USA and SHAM was tap water delivered in a like manner. The US for Groups FOR, BKD, USA, and RAN was a $1.0-\mathrm{ml}$ injection of .15-M LiCl administered IP, while the sham US for Groups CSA and SHAM was $1.0 \mathrm{ml}$ physiological saline.

The training sessions were halted on the 8th day when the subjects in Group FOR began to manifest overt signs of aversion to the saccharin solution. That is, relative to their behavior on the preceding trials, and in comparison with the control groups, the rats in Group FOR rejected the saccharin that was syringed into their mouths by (a) not licking the syringe, (b) not swallowing the saccharin, and (c) in some instances squealing, attempting to escape handling, and biting the syringe. All subjects were then put on a deprivation schedule that allowed them $15 \mathrm{~min}$ access to water per day. Water was presented only in the Plexiglas testing cages, while food consumption remained ad lib in their home cages.

On the 4th posttraining day, preference testing sessions began, i.e., one 15-min trial per day for 4 days. During each session, the saccharin solution was presented in one Richter tube and tap water in the other. A position effect was controlled for by reversing the tubes after each session. The saccharin consumption relative to the total fluid consumption was recorded daily, and a saccharin preference score for each rat was computed by dividing saccharin consumed by total fluid intake.

\section{RESULTS}

An arc sin transformation was carried out on the saccharin preference scores of each subject. The mean transformed scores for all groups over the 4 test days are shown in Figure 1.

A split-plot analysis of variance of the transformed preference scores of the six groups across 4 extinction days (Kirk, 1968) was conducted, and both main effects and their interaction were significant [Groups $F(5,42)=9.273$, p $<.01$; Extinction $F(3,126)=$ $44.717, \mathrm{p}<.01$; Groups by Extinction $F(15,126)=$ $2.198, \mathrm{p}<.05$ ). Conditioned saccharin aversion occurred in the forward conditioning groups as evidenced by the fact that post hoc comparisons of each control group with the forward conditioning group using Dunn's procedure were significant $(\mathrm{p}<.05)$.

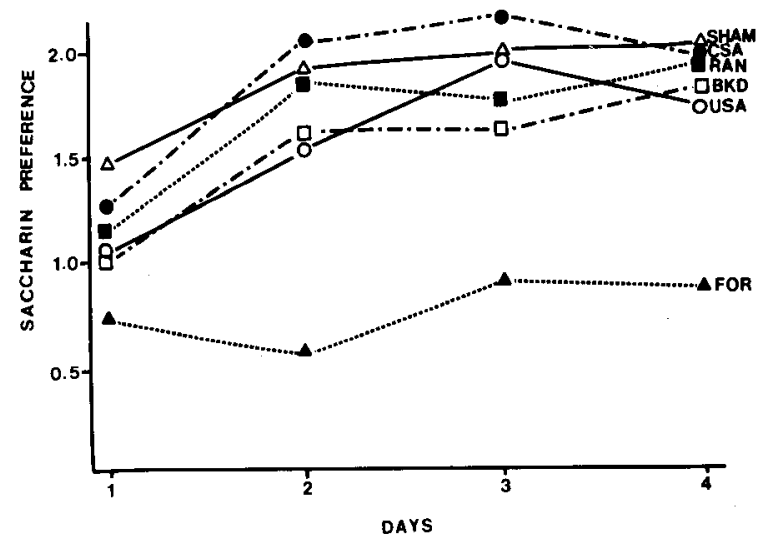

Figure 1. Mean arc sin transformed saccharin preference scores for the six groups plotted as a function of Extinction Days $1-4$.
The control procedures were analyzed by comparing each group with Group SHAM. It was found that the saccharin preferences of Groups CSA, USA, RAN, and BKD did not differ from that of Group SHAM (all ps $>.05$ ). In addition, Group RAN and Group BKD differed neither from each other nor from any of the other control groups (all ps $>.05$ ).

\section{DISCUSSION}

An important finding of this experiment is that saccharin aversions were not found in groups that had either (CS alone, US alone) or both (backward, random) stimulus elements present during training. Both stimulus elements plus the appropriate temporal sequencing were necessary for aversion formation. The results support recent contentions (Garcia, 1978; Revusky, 1977, 1978; Smith, 1978) that the associative nature of taste aversions formation has been established beyond reasonable doubt.

Powerful nonassociative effects are often found in taste aversion studies, including the attenuation of flavor neophobia through preexposure to the flavor (Domjan, 1976, 1977; Siegel, 1974) or enhancement of neophobia through pretreatment with a toxin (Carroll, Dinc, Levy, \& Smith, 1975; Domjan, 1975). Both the number and the duration of prior flavor exposures influence the extent of increase in subsequent flavor intake (Domjan, 1976). The reason for the failure to see this effect in the present study is not clear, although presumably differences in the flavor of the CS and patternings of flavor preexposure are critical variables. Siegel (1974), for example, reported that as little as $8.7 \mathrm{~min}$ preexposure to either a coffee or vinegar flavor via infusion through an oral cannula produced enhanced consumption of that flavor, even when 24 days intervened before the second flavor test. Domjan (1976, Experiment 4) found that oral infusion of $6 \mathrm{ml}$ of a highly concentrated $(2.0 \%)$ saccharin solution on two occasions separated by $10 \mathrm{~min}$ (total flavor duration $=4 \mathrm{~min}$ within a 14 min period) produced the preexposure effect. In the present experiment, eight separate $1.0-\mathrm{ml}$ saccharin exposures over 8 days (total duration $=4.0 \mathrm{~min}$ within 8 days) yielded no preexposure effect.

We agree with Domjan that both the duration and patternings of preexposure are critical to the development of the flavor preexposure effect. Our results are compatible with a model of the development of flavor memory in which brief-duration stimulus events are relatively quickly forgotten (cf, trace decay) unless a significant reinforcing or aversive stimulus is placed in continguity with that trace. Longer duration flavor presentations, or more presentations of shorter duration, or repeated presentations with short intervals between them appear to be necessary for that flavor to have an effect on memory in the absence of a following aversive stimulus. Relatively long-duration flavor stimuli, when followed by an aversive stimulus, yield better conditioning. This, it has been argued, is 
indicative of a better memory for the flavor at the time of the CS-US pairing (Barker, 1976).

There are two lines of evidence which seem to suggest that Group USA should have shown enhanced neophobia to saccharin on the first test day relative to Group SHAM. Rats which drink water (CS) followed by lithium injection (US) have been found to drink less saccharin during an initial test. Barker and Smith (1974) postulated a "punishment of ingestion" effect to account for this. Domjan (1975) also reported enhanced neophobia in a group receiving a prior noncontingent lithium injection. The present finding that eight preexposures to a small amount of lithium chloride did not affect subsequent saccharin acceptance should perhaps not be too surprising, however. Domjan reported that the effect was not reliably produced, and Carroll et al. (1975) found the effect only within $24 \mathrm{~h}$ following administration of a dosage of lithium which was four times that used in the present study. It appears likely that enhanced neophobia may only be produced under certain optimal conditions, including pretreatment with large dosages of toxins.

One-trial acquisition and the association of CSs with USs over a long delay have been cited as evidence that taste aversion conditioning is a unique form of learning (Garcia, McGowan, \& Green, 1972; cf. Seligman, 1970). According to this analysis, socalled "standard" demonstrations of animal learning, such as CER conditioning in rats, require both temporal contiguity of CS and US and several trials for learning to occur. When an auditory stimulus is paired with footshock, for examle, CS-US delays of more than 2-3 min cannot be tolerated, and several trials are necessary for acquisition even when intense stimuli are used (Kamin, 1965).

The results of the present experiment resemble the outcome of such standard animal learning experiments. Reliable signs of avoidance acquisition were not seen until the sixth trial, with most animals in Group FOR avoiding administration of the oral rinse CS by the eighth trial. By contrast, there are numerous reports of long lasting, one-trial aversions conditioned to saccharin using lithium as the US over $6-8-\mathrm{h}$ delays when the CS duration was 10 or more minutes (Barker \& Smith, 1974; Nachman, 1970). The present findings suggest that small amounts of a flavor probably cannot be associated over relatively long CS-US delays, given that learning even a short $(1 / 2-h)$ delay required a number of trials. Our lithium dosage (.75-mEq lithium) was low relative to the studies finding conditioning over 6-8 $\mathrm{h}$ (both used $3.0 \mathrm{mEq}$ ). We do not attribute the necessity of multiple trials to effect conditioning to a low lithium dosage, however. Nachman and Ashe (1973) found .6 mEq to be effective in conditioning one-trial sucrose aversions over 12 - to 15 -min delays. The many trials necessary for conditioning aversion to $.25 \%$ saccharin, which is a more salient flavor than sucrose, can more likely be attributed to the small CS amounts used.

\section{REFERENCES}

BARKER, L. M. CS duration, amount, and concentration effects in conditioning taste aversions. Learning and Motivation, 1976, 7, 265-273.

Barken, L. M., \& SMith, J. C. A comparison of taste aversions induced by radiation and lithium chloride in CS-US and US-CS paradigms. Journal of Comparative and Physiological Psychology, 1974, 87, 644-654.

Bitterman, M. E. Flavor aversion studies. Science, 1976, 192, 266-267.

Carroll, M. E., Dinc, H. I., Levy, C. J., \& Smith, J. C. Demonstrations of neophobia and enhanced neophobia in the albino rat. Journal of Comparative and Physiological Psychology, 1975, 89, 457-467.

Domjan, M. Poison-induced neophobia in rats: Role of stimulus generalization of conditioned taste aversions. Animal Learning \& Behavior, 1975, 3, 205-211.

Domuan, M. Determinants of the enhancement of flavored-water intake by prior exposure. Journal of Experimental Psychology: Animal Behavior Processes, 1976, 2, 17-27.

Domjan, M. Attenuation and enhancement of neophobia for edible substances. In L. M. Barker, M. R. Best, \& M. Domjan (Eds.), Learning mechanisms in food selection. Waco, Tex: Baylor University Press, 1977.

GarCiA, J. Mitchell, Scott, \& Mitchell are not supported by their own data. Animal Learning \& Behavior, 1978, 6, 116.

Garcia, J., \& Kimeldorf, D. J. Temporal relationship within the conditioning of a saccharin aversion through radiation exposure. Journal of Comparative and Physiological Psychology, 1957, 50, 180-183.

Garcia, J., Kimmeldorf, D. J., \& Koelling, R. A. Conditioned aversion to saccharin resulting from exposure to gamma radiation. Science, 1955, 122, 157-158.

Garcia, J., McGowan, B. K., \& Green, K. F. Biological constraints on conditioning. In A. H. Black \& W. F. Prokasy (Eds.), Classical conditioning II: Current research and theory. New York: Appleton-Century-Crofts, 1972.

KAmin, L. J. Temporal and intensity characteristics of the conditioned stimulus. In W. F. Prokasy (Ed.), Classical conditioning. New York: Appleton-Century-Crofts, 1965.

KIRK, R. E. Experimental design: Procedures for the behavioral sciences. Belmont, Calif: Brooks/Cole, 1968.

Mitchell, D. Reply to Revusky. Animal Learning \& Behavior, 1977, 5, 321-322.

Mitcheld, D. The psychological vs. the ethological rat: Two views of the poison avoidance behavior of the rat compared. Animal Learning \& Behavior, 1978, 6, 131-134.

Nachman, M. Learned taste and temperature aversions due to lithium chloride sickness after temporal delays. Journal of Comparative and Physiological Psychology, 1970, 73, 22-30.

Nachman, M., \& Ashe, J. H. Learned taste aversions in rats as a function of dosage, concentration, and route of administration of LiCl. Physiology and Behavior, 1973, 10, 73-78.

Rescorla, R. A. Pavlovian conditioning and its proper control procedures. Psychological Review, 1967, 74, 71-80.

Revusky, S. H. Correction of a paper by Mitchell, Scott, and Mitchell. Animal Learning \& Behavior, 1977, 5, 319.

Revusxy, S. H. Reply to Mitchell. Animal Learning \& Behavior, 1978, 6, 119-120.

Szligman, M. E. P. On the generality of the laws of learning. Psychological Review, 1970, 77, 406-418.

Steate, S. Flavor preexposure and "learned safety." Journal of Comparative and Physiological Psychology, 1974, 87, 1073-1082.

Smith, J. C. Comment on paper by Mitchell, Scott, and Mitchell. Animal Learning \& Behavior, 1978, 6, 117-118.

(Received for publication June 30, 1978; revision accepted October 6, 1978.) 